\title{
Expression of a disintegrin and metalloprotease (ADAM and ADAMTS) enzymes in human non-small-cell lung carcinomas (NSCLC)
}

\author{
N Rocks', G Paulissen', F Quesada Calvo', M Polette'2, M Gueders', C Munaut', J-M Foidart', A Noel', \\ $P$ Birembaut ${ }^{2}$ and D Cataldo*,I
}

'Laboratory of Pneumology and Laboratory of Tumor and Development Biology, Center for Biomedical Integrative Genoproteomics (CBIG), University of Liège and Centre Hospitalier Universitaire de Liège (CHU-Liège), Avenue de l'Hôpital, CHU, Sart-Tilman, Liège 4000, Belgium; ${ }^{2}$ INSERM U5 I4,

Laboratory Pol Bouin, Hôpital Maison Blanche CHU, Reims, France

\begin{abstract}
A Disintegrin and Metalloprotease (ADAM) are transmembrane proteases displaying multiple functions. ADAM with ThromboSpondin-like motifs (ADAMTS) are secreted proteases characterised by thrombospondin (TS) motifs in their C-terminal domain. The aim of this work was to evaluate the expression pattern of ADAMs and ADAMTS in non small cell lung carcinomas (NSCLC) and to investigate the possible correlation between their expression and cancer progression. Reverse transcriptasepolymerase chain reaction (RT-PCR), Western blot and immunohistochemical analyses were performed on NSCLC samples and corresponding nondiseased tissue fragments. Among the ADAMs evaluated (ADAM-8, -9, - 10, - 12, - I5, - I7, ADAMTS- I, TS-2 and TS-12), a modulation of ADAM- 12 and ADAMTS-I mRNA expression was observed. Amounts of ADAM- 12 mRNA transcripts were increased in tumour tissues as compared to the corresponding controls. In sharp contrast, ADAMTS-I mRNA levels were significantly lower in tumour tissues when compared to corresponding nondiseased lung. These results were corroborated at the protein level by Western blot and immunohistochemistry. A positive correlation was observed between the mRNA levels of ADAM12 and those of two vascular endothelial growth factor (VEGF)-A isoforms (VEGF-A 165 and VEGF-A 121 ). Taken together, these results providing evidence for an overexpression of ADAM- 12 and a lower expression of ADAMTS-I in non-small-cell lung cancer suggest that these proteases play different functions in cancer progression.
\end{abstract}

British Journal of Cancer (2006) 94, 724-730. doi:I0.1038/sj.bjc.6602990 www.bjcancer.com

Published online 2I February 2006

(c) 2006 Cancer Research UK

Keywords: ADAM; ADAMTS; lung; proteinases; VEGF

Lung cancer is one of the most common causes of cancer death in Europe and in the United States and disease frequency rapidly increased over the last decades. Accumulating evidence demonstrated the important role of proteolytic enzymes such as matrix metalloproteinases (MMPs) in cancer progression (Egeblad and Werb, 2002; Overall and Lopez-Otin, 2002; Handsley and Edwards, 2005). In contrast, to date, no information is available on the putative relationship existing between lung cancers and MMPrelated enzymes such as A Disintegrin and Metalloprotease (ADAM) and ADAM with ThromboSpondin-like motifs (ADAMTS) proteases.

A disintegrin and metalloprotease is a family of transmembrane proteases displaying multiple functions among which 21 human ADAM genes likely encode active proteases (Puente et al, 2003). A disintegrin and metalloprotease with thrombospondin (TS)-like motifs are secreted molecules bearing TS motifs in their C-terminal domain (Killar et al, 1999; Kaushal and Shah, 2000; Tang, 2001; Cal et al, 2002). On the basis of their structure, ADAMs and ADAMTS are thought to mediate a wide variety of activities including proteolysis, adhesion, cell fusion and signalling (Porter et al, 2005).

*Correspondence: Dr D Cataldo; E-mail: Didier.Cataldo@ulg.ac.be Received 19 September 2005; revised 21 December 2005; accepted 17 January 2006; published online 2I February 2006
Although their functions are not yet fully elucidated, an upregulation of ADAMs and ADAMTS has been observed in some pathological conditions. A recent report suggests that ADAM- 8 is overexpressed by lung cancer cells and is detectable in patient's serum (Ishikawa et al, 2004). A disintegrin and metalloprotease-10 is upregulated in some tumour cells (Wu et al, 1997) and in arthritic chondrocytes (McKie et al, 1997). A disintegrin and metalloprotease-12 and 15 are also abundantly expressed in cells derived from haematological malignancies (Wu et al, 1997). Monocytes from lung cancer patients produce elevated levels of mature TNF- $\alpha$ (Trejo et al, 2001) which could result from the shedding of pro-TNF- $\alpha$ by ADAM-17 (TACE) (Black et al, 1997). ADAM with TS-like motifs-1 (ADAMTS-1) is expressed in colon cancer cells (Kuno et al, 1997).

Even if the implication of ADAMs and ADAMTS during lung cancer progression remains unclear, it is conceivable that, as shown for MMPs, these related proteases contribute to extracellular matrix degradation, cell-cell adhesion, cell proliferation, cell migration as well as to the processing of cytokines or growth factors (Egeblad and Werb, 2002; Overall and Lopez-Otin, 2002; Handsley and Edwards, 2005). The putative interest of studying ADAMs and ADAMTS in lung carcinomas is reinforced by a recent report of Lemjabbar et al (2003), demonstrating that tobacco smoke-induced bronchial epithelial cell proliferation is mediated by the cleavage of amphiregulin, a ligand of EGF receptor, by 
ADAM-17. A disintegrin and metalloprotease-15 (ADAM-15) deficiency in mice is associated with impaired pathological angiogenesis and reduced tumour growth (Horiuchi et al, 2003). In addition, recently, an interplay between vascular endothelial growth factor (VEGF) and metalloproteases has been reported. This new concept is supported by (1) the ability of ADAMTS-1 to bind VEGF and functionally inactivate VEGFR2 (Iruela-Arispe et al, 2003), (2) the existence of a correlation between VEGF and some MMP expression in tumours, (3) the upregulation of VEGFA expression by the active form of membrane type-1 MMP (MT1MMP, MMP14) (Munaut et al, 2003), (4) the reduction of VEGF expression in tumour cells by physiological inhibitor (TIMP-2) (Hajitou et al, 2001) or synthetic inhibitor (Sounni et al, 2004) of MMPs. These observations suggest the involvement of ADAM, ADAMTS and MMP members in the control of angiogenesis, a key step of metastatic dissemination.

The aim of the present work was to determine the expression profile of selected ADAMs and ADAMTS in NSCLC as well as to study the putative correlation existing between these proteases and VEGF isoform expression levels and the disease stage.

\section{MATERIALS AND METHODS}

\section{Tumour tissue samples}

Surgical samples from non-small-cell lung tumours and corresponding lung control tissues were obtained from 39 patients with squamous cell lung cancers or adenocarcinomas. Characteristics of patients and histological subtypes are described in Table 1. The protocol of the study was approved by the Ethical Committee of the Hôpital Maison Blanche, Reims and informed consent was obtained from all patients before surgery.

\section{Cell culture and RNA isolation}

Lung cancer cell lines: BEAS-2B were purchased from ATCC, while BZR, BZR-T33, and 16-HBE were kindly provided by Dr CC Harris (National Institute of Health, Bethesda, MD, USA). All cell lines were cultured in Dulbecco's modified Eagle's medium (DMEM, Invitrogen, Merelbeke, Belgium) supplemented with $10 \%$ foetal bovine serum, $5 \%$ penicillin - streptomycin (Invitrogen, Merelbeke, Belgium) and $5 \%$ glutamine in $5 \% \mathrm{CO}_{2}$ at $37^{\circ} \mathrm{C}$. BEAS-2B cells were cultured in collagen-coated Petri dishes in Airway Epithelial Cell Basal Medium (Promocell, Heidelberg, Germany).

Total RNAs were extracted from normal and tumoral lung tissues as well as from 16-HBE, BZR, BZR-T33 and BEAS-2B cells by the use of the RNA Easy Qiagen Kit (Qiagen, MD, USA). Total RNA concentrations were measured using the RiboGreen RNA quantification Kit (Molecular Probes, OR, USA). Samples were stored at $-80^{\circ} \mathrm{C}$.

\section{Design of oligonucleotide primers}

The design of oligonucleotide primers specific for the different targets was based on sequences available in the Genbank. Primers, obtained from Eurogentec (Seraing, Belgium), were designed to anneal to distinct exons and the specificity of the selected sequences was verified with the NCBI BLASTN program (Table 2). Polymerase chain reaction products obtained with each pair of primers were digested with appropriate restriction enzymes to verify the specificity of amplification.

\section{Semiquantitative RT - PCR}

The mRNA expression levels of ADAMs, ADAMTS and VEGF-A were determined by semiquantitative RT-PCR. Reverse

Table I Characteristics of tumours and patients

\begin{tabular}{lcc}
\hline & Adenocarcinoma & Squamous cell \\
\hline Number of samples & 26 & 13 \\
Mean age & 60 & 67 \\
Sex ratio $(M / F)$ & $22 / 4$ & $12 / 1$ \\
$T$ & $T_{1}: 2$ & $T_{1}: 2$ \\
& $T_{2}: 20$ & $T_{2}: 9$ \\
& $T_{3}: 4$ & $T_{3}: 2$ \\
$N$ & $N_{0}: 15$ & $N_{0}: 6$ \\
& $N_{1}: 5$ & $N_{1}: 7$ \\
& $N_{2}: 5$ & \\
$N_{3}: 1$ & \\
$M$ & $M_{0}: 26$ & $M_{0}: 13$ \\
\hline
\end{tabular}

The staging reported here is the histological staging obtained after surgical resection

Table 2 Primer sequences designed for RT-PCR studies

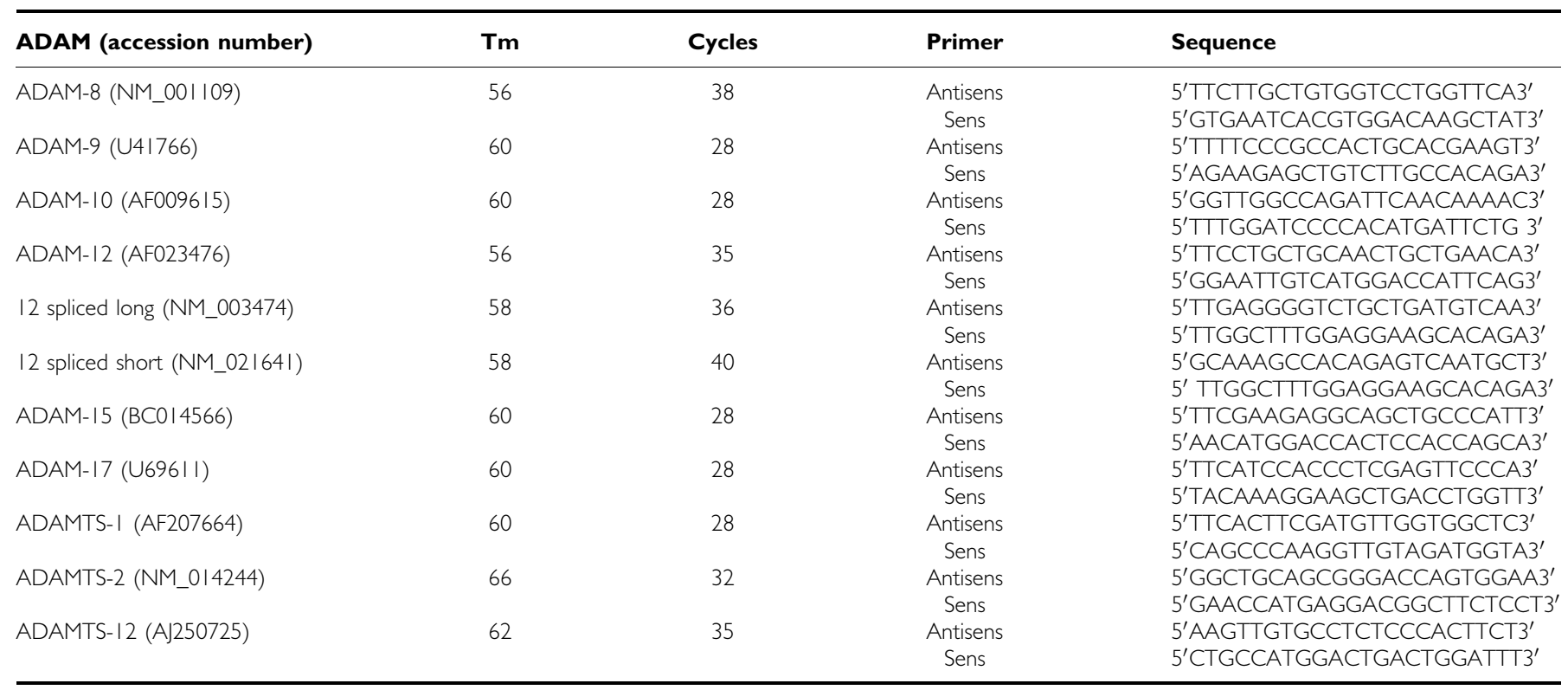


transcriptase-polymerase chain reaction was performed on $10 \mathrm{ng}$ of total RNA at $70^{\circ} \mathrm{C}$ during $15 \mathrm{~min}$ using the GenAmp thermostable RNA RT - PCR Kit (Applied Biosystems, Foster City, CA, USA). Reverse transcriptase-polymerase chain reaction conditions and primers used to measure VEGF-A expression were those previously described (Hajitou et al, 2001). The intensity of each band was measured with the Quantity One software (Biorad, Hercules, USA). To normalise mRNA levels in different samples, the value of the band corresponding to each mRNA level was divided by the intensity of the corresponding $28 \mathrm{~S}$ rRNA band used as an internal standard.

\section{Real-time PCR}

Total RNA $(500 \mathrm{ng})$ was reverse transcribed in a $15 \mu$ l reaction using $50 \mathrm{ng}$ of random hexamers and ThermoScript reverse transcriptase (Life Technologies, Paisley, UK) according to the manufacturer's instructions. Primers for ADAM-12 and ADAMTS1 as well as the corresponding TaqMan probe were designed using PRIMER EXPRESS 1.0 software (Applied Biosystems, Foster City, CA, USA). In order to avoid genomic DNA amplification, primers were chosen within different exons, close to intron-exon boundaries. The $18 \mathrm{~S}$ ribosomal RNA gene was used as an endogenous control to normalise RNA amounts in each sample. TaqMan 18S ribosomal primers as well as the VIC-labelled probe were used according to the manufacturer's instructions (Applied Biosystems, Foster City, CA, USA). Polymerase chain reaction (PCR) reactions were performed on a 96-well optical plate with the Platinum Super Mix (Invitrogen, Paisley, UK) using $5 \mu \mathrm{l}$ of diluted cDNA (equivalent to $10 \mathrm{ng}$ total RNA), $200 \mathrm{nM}$ of the probe and $400 \mathrm{~nm}$ primers in a $25 \mu \mathrm{l}$ final reaction mixture. Each of the $40 \mathrm{PCR}$ cycles consisted of $15 \mathrm{~s}$ of denaturation at $95^{\circ} \mathrm{C}$ and hybridisation of probes and primers for $1 \mathrm{~min}$ at $60^{\circ} \mathrm{C}$. Real-time quantitative PCR analyses for ADAM-12 and ADAMTS- 1 were performed using the ABI PRISM 7700 Sequence Detection System instrument and software (Applied Biosystems, Foster City, CA, USA). The amount of target gene was divided by the 18S rRNA amount to obtain a normalised target value. Each experiment was performed in duplicate and the Standard Error of mean (s.e.m) has been calculated on the basis of the two experiments.

\section{Western blot analysis}

Proteins were isolated from tumour and control tissues by urea extraction (Cataldo et al, 2002). Samples were migrated on a $12 \%$ polyacrylamide gel and transferred to a PVDF membrane (Perkin Elmer Life Sciences Inc., Boston, MA, USA). In order to normalise Western blots data, tissue extracts corresponding to $20 \mu \mathrm{g}$ of total proteins were loaded for each patient. Anti-ADAM-12 (1/100) or anti-ADAMTS-1 (1/500) antibody (Santa Cruz Biotechnologies Inc., Sigma-Aldrich, Belgium) was applied overnight. Proteins were finally detected by chemiluminescence with rabbit anti-goat-IgG (DAKO, Glostrup, Denmark) diluted 1/1000 coupled with HRP immunoreactives.

\section{Immunohistochemistry}

Tissue sections were incubated for $1 \mathrm{~h}$ with polyclonal antibodies recognising either ADAM-12 (Sigma, St Louis, MI, USA) or ADAMTS-1 (Santa Cruz Biotechnologies Inc., Santa Cruz, CA, USA) protein and after rinsing were incubated for $30 \mathrm{~min}$ with anti-rabbit antibodies coupled to horseradish peroxidase-labelled dextran polymers (Envision, DAKO, Glostrup, Denmark) for ADAM-12 or with rabbit anti-goat IgG antibodies (DAKO, Glostrup, Denmark) for ADAMTS-1. Slides were finally incubated with 3-amino-9-ethylcarbazol (AEC) (DAKO, Glostrup, Denmark) and the sections were counterstained with haematoxylin.

\section{Statistical analysis}

Data are reported as mean \pm s.e.m. and statistical analysis was performed by the Mann-Whitney test. Correlations were measured by the Spearman's test. The threshold for significance was set at $P<0.05$.

\section{RESULTS}

\section{Semiquantitative RT-PCR and real-time PCR}

Polymerase chain reaction analyses were performed on NSCLC obtained by surgery from 34 men and five women. Table 1 summarises the characteristics of patients, their TNM states based on pathological examination (pTNM) and histological subtype of tumours. The mRNA expression levels were determined on each human tumour sample and their corresponding control lung tissue by semiquantitative RT-PCR (Table 3). Among ADAMs and ADAMTS evaluated, a difference in ADAM-12 and ADAMTS-1 mRNA levels was evidenced between cancer and control samples. In contrast, no modulation of ADAM-8, -9, -10, -15, -17 and ADAMTS-2 and -12 was observed in the two sample groups (Table 3). Interestingly, the amounts of ADAM-12 transcripts normalised to $28 \mathrm{~S}$ rRNA were significantly higher in lung tumours when compared to the matched normal tissues $(P=0.0005)$ (Figure 1A). Inversely, ADAMTS-1 mRNA was expressed at lower levels in tumour samples than in normal lung tissues $(P<0.0001)$ (Figure 1B). To confirm these results, quantitative real-time PCR was then performed. Amounts of ADAM-12 transcripts were confirmed to be significantly increased in tumours $(0.2 \pm 0.03$ in tumours $v s 0.04 \pm 0.006$ in normal tissues; $P<0.0001)$ (Figure $1 \mathrm{E}$ ). Again, amounts of ADAMTS-1 mRNA copies were found to be lower in tumours than in control samples $(4.9 \pm 0.57$ in tumours $v s$ $17.8 \pm 2.7$ in controls; $P<0.0001$ ) (Figure $1 \mathrm{~F}$ ).

Since two forms of ADAM-12 resulting from an alternative splicing have been described, two additional pairs of primers have been designed near to the splicing region to determine the relative amounts of these isoforms. ADAM-12L (membrane-bound long variant) transcripts were overexpressed in tumours when compared to controls, while no expression of short form of ADAM-12 (ADAM-12S) (secreted short variant) was detected in the lung tissues examined (Figure 2). This result demonstrates that almost the vast majority of ADAM-12 expressed in tumour tissue corresponds to the membrane-bound form of ADAM- 12 .

No significant differences were found regarding expression levels of ADAM-12 and ADAMTS-1 when considering the different TNM states or survival (data not shown). However, in the adenocarcinoma subgroup, we showed an increase of ADAM-12 mRNA in the N0 stages when compared to N1 or N2 stages. There were no significant differences for the expression of any ADAM or

Table 3 Expression pattern of several ADAMs and ADAMTS in nonsmall-cell lung carcinomas measured by semiquantitative RT-PCR

\begin{tabular}{lcc}
\hline & Tumours & Controls \\
\hline ADAM-8 & $0.06 \pm 0.006$ & $0.05 \pm 0.01$ \\
ADAM-9 & $0.6 \pm 0.1$ & $0.3 \pm 0.07$ \\
ADAM-10 & $0.7 \pm 0.14$ & $0.34 \pm 0.07$ \\
ADAM-12 & $0.3 \pm 0.09 *$ & $0.05 \pm 0.004$ \\
ADAM-15 & $0.8 \pm 0.11$ & $0.46 \pm 0.07$ \\
ADAM-17 & $0.2 \pm 0.07$ & $0.16 \pm 0.03$ \\
ADAMTS-1 & $0.19 \pm 0.05 *$ & $0.3 \pm 0.06$ \\
ADAMTS-2 & $0.31 \pm 0.07$ & $0.37 \pm 0.11$ \\
ADAMTS-12 & $0.3 \pm 0.08$ & $0.23 \pm 0.05$ \\
\hline
\end{tabular}

Results are expressed as arbitrary units $(\mathrm{AU})$ (mean \pm s.e.m.) and are normalised for $28 \mathrm{~S}$ rRNA expression. $*=P<0.05$ vs controls. 
A

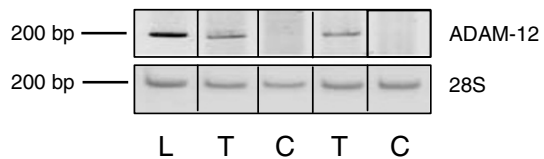

C

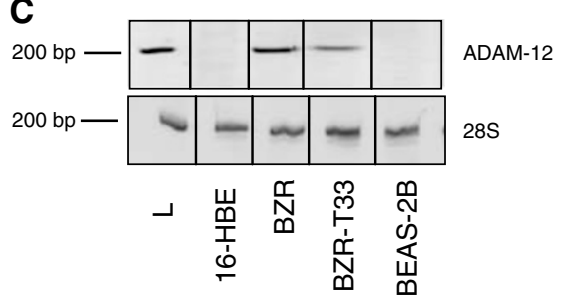

B

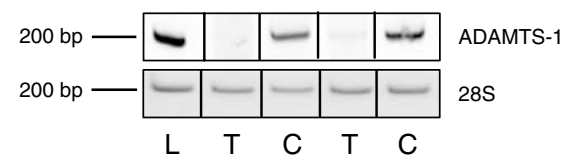

D

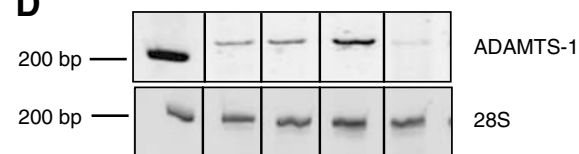

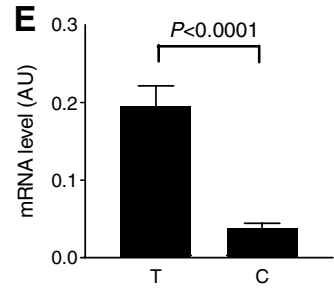

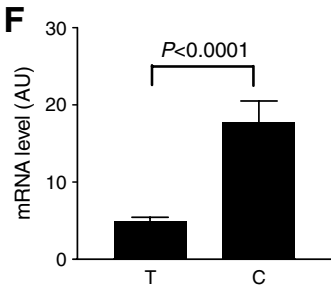

Figure I RT-PCR analysis of ADAM- 12 and ADAMTS-I in human tumour samples and normal lung tissues $(n=39)$ and in lung cancer cell lines. $(\mathbf{A})$ mRNA transcripts of total ADAM-12. The expression of ADAM-12 mRNA is significantly higher in tumours (T) than in their control tissues (C). (B) Expression of ADAMTS-I mRNA. ADAMTS-I expression is lower in tumour tissues when compared to the corresponding control tissue. L: 200 bp molecular weight (Smart Ladder, Eurogentec, Seraing, Belgium). (C-D) ADAM- I2 (left panel) and ADAMTS-I (right panel) mRNA expression in human lung cancer cell lines. The bottom line represents the 28S RNA. (E-F) Results of quantitative real-time PCR for ADAM- I2 and ADAMTS-I, expressed as arbitrary units (AU) normalised to the I8S rRNA (described in the Materials and Methods section).

A

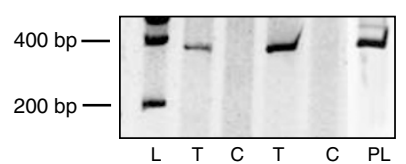

B

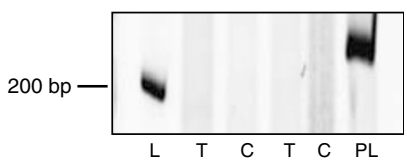

Figure 2 RT-PCR analysis of spliced variants of ADAM-I2. Long membrane-anchored variant (ADAM-I2L) and short secreted variant (ADAM-I2S) in tumour and normal lung tissue $(n=39)$. (A) mRNA expression of ADAM-I2L. The expected molecular weight was $340 \mathrm{bp}$ for ADAM-I2L. (B) mRNA expression of ADAM-12S. The expected molecular weight was $220 \mathrm{bp}$ for the short form. L: $200 \mathrm{bp}$ molecular weight, T: tumoral tissue, (C): corresponding control tissue. PL: human placental mRNA used as control.

ADAMTS protease between the squamous cell and adenocarcinoma groups.

We next analysed ADAM expression in human epithelial lung cell lines (16-HBE, BZR, BZR-T33 and BEAS-2B cells). Almost all cell lines tested expressed ADAM-9, -10, -12, -15 and ADAM-17 (data not shown). A disintegrin and metalloprotease-12 mRNA were not detected in immortalised BEAS-2B and 16-HBE cells derived from normal epithelial cells (Figure 1C). In sharp contrast, ADAM-12 was strongly expressed in two cell lines, BZR and BZRT33, derived from BEAS-2B cells by infection with recombinant retrovirus Zip-neo-v-Ha-ras or derived from a tumour formed by BZR cells injected subcutaneously into nude mouse, respectively. These two cell lines expressing ADAM-12 (BZR and BZR-T33) have been reported to display a more invasive behaviour when implanted in mice (Bonfil et al, 1989) than cells not expressing ADAM-12 (BEAS-2B; 16-HBE). ADAM with TS-like motifs-1 (ADAMTS-1) mRNA expression was also investigated in these cell lines (Figure 1D).

\section{Western blot analysis}

The activation status of ADAM-12 and ADAMTS-1 in tumours and corresponding control tissues was investigated by Western blotting. The $97 \mathrm{kDa}$ proform and the $77 \mathrm{kDa}$ activated form of ADAM-12L were detectable in samples (Figure 3A). The results confirm at the protein level the significant increase in tumour samples $v s$ control samples observed at the mRNA level. Moreover, the ratio between activated and proforms was higher in tumours than in corresponding controls (65.8 \pm 3.85 vs $54 \pm 3.91)$ (Figure 3C).

No difference in ADAMTS-1 production was observed between tumour and control samples (Figure 3B and D).

\section{VEGF-A semiquantitative RT - PCR}

The analysis of VEGF-A mRNA expression revealed an overexpression of VEGF- $\mathrm{A}_{121}$ and VEGF- $\mathrm{A}_{165}$ (Figure $4 \mathrm{~A}$ and $\mathrm{B}$ ) and lower levels of VEGF-A 189 mRNA (Figure 4C) in all tumour samples when compared to corresponding control lungs. A positive correlation was observed between the mRNA levels of ADAM-12 and those of VEGF-A $A_{121}(P<0.0001)$ or VEGF-A 165 $(P<0.0001)$ in tumour samples (Figure $4 \mathrm{D}$ and $\mathrm{E})$. Vascular endothelial growth factor- $\mathrm{A}_{121}$ expression was also significantly increased in tumours displaying N2 status as compared to those without nodal involvement (N0).

\section{Immunohistochemistry}

A disintegrin and metalloprotease-12 immunoreactivity was mainly detected in tumour cells (Figure 5A and B). Some immunostaining was also observed, as expected, in normal smooth muscle surrounding the tumour. In normal lung, some inflammatory cells were positively stained while epithelial cells were always negative. 


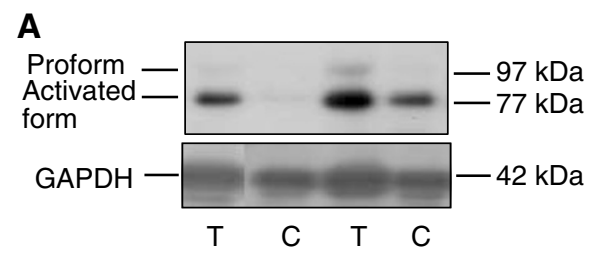

B
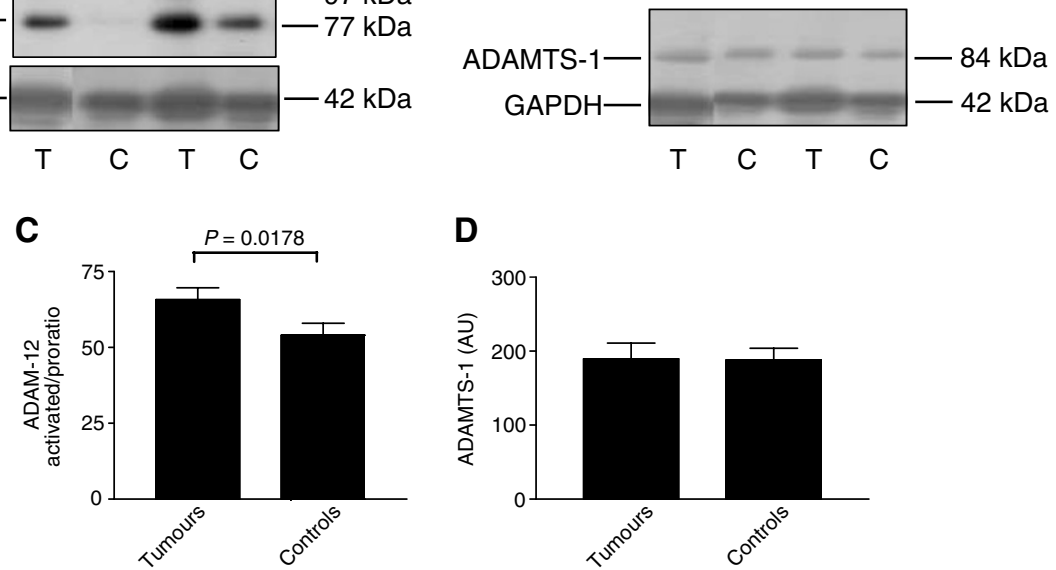

Figure 3 Western blotting of ADAM- 12 protein immunoreactivity $(\mathbf{A})$ and ADAMTS-I $(\mathbf{B})$ in normal and tumour lung tissues $(n=39)$. For each sample, the lower panel corresponds to the house keeping gene product glyceraldehyde-3-phosphate dehydrogenase (GAPDH) used as a loading control. T: tumour tissue, C: control tissue. ADAM- 12 activated/proratio (densitometric analysis of the immunoreactivity of the activated form of ADAM- 12 (77 kDa) normalised by the immunoreactivity of the proform $(97 \mathrm{KDa})$ ) $(\mathbf{C})$ and levels of immunoreactivity corresponding to activated ADAMTS-I (84 kDa) (D).
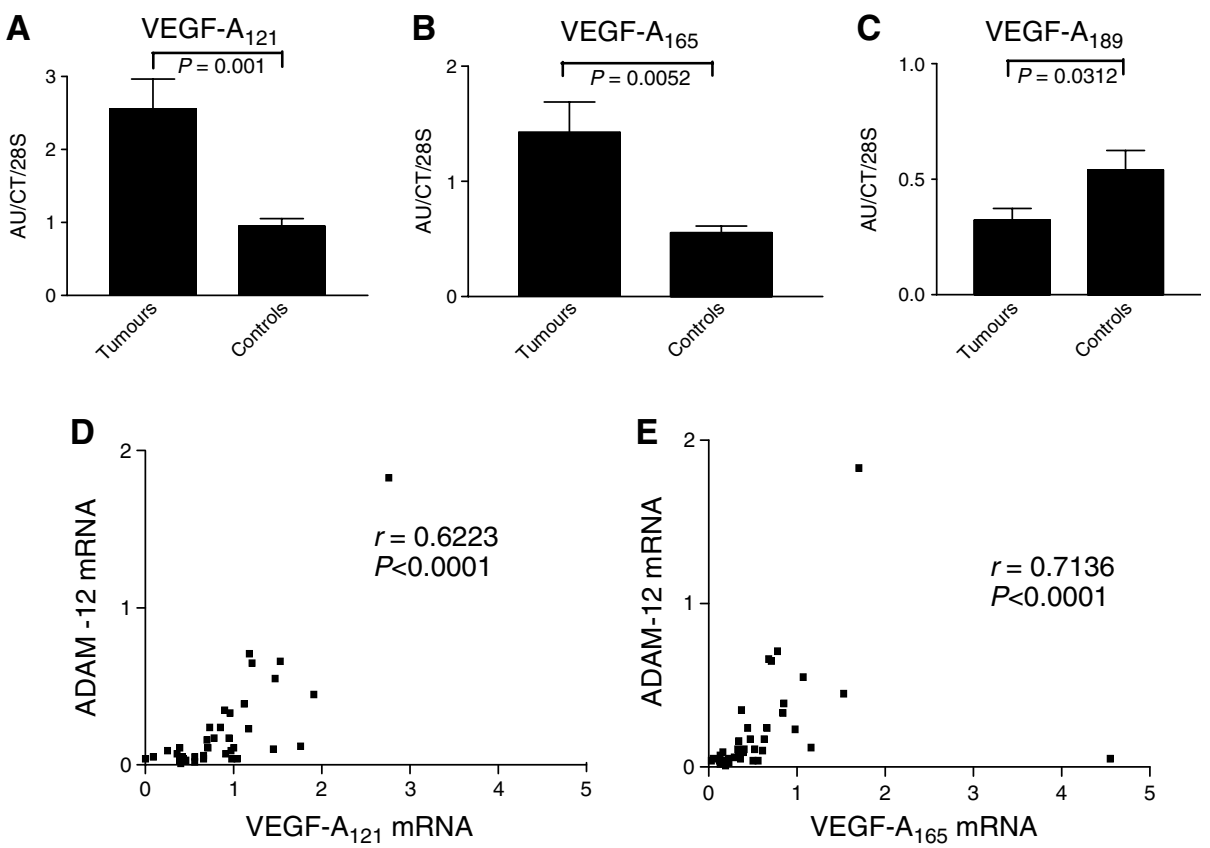

Figure 4 VEGF-A $\mathrm{A}_{121}$ and VEGF-A $\mathrm{A}_{165}$ mRNA levels are more elevated in tumour samples $(T)(P<0.05)(\mathbf{A}-\mathbf{B})$ while VEGF-A 189 mRNA levels are lower in the squamous carcinomas and adenocarcinomas $(P<0.00 \mathrm{I})(\mathbf{C})$. Results are expressed as arbitrary units $(A \cup)$ divided by the values of an internal control and are normalised for the amount of 28S rRNA. In tumour samples, a positive correlation between ADAM-12 and VEGF-A 121 (D) and VEGF 165 (E) mRNA levels has been observed $(P<0.000 \mathrm{I})$.

ADAMTS-1 immunoreactivity was mostly seen in normal epithelial bronchial cells in control lung tissues as well as in normal bronchi surrounding tumour nodules in diseased lung (Figure 5C and D). The transition of normal epithelial cells into tumour cells was associated with a loss of ADAMTS-1 immunostaining.

\section{DISCUSSION}

The present study was designed to investigate the potential involvement of ADAMs and ADAMTS in the pathogenesis of lung carcinomas. Indeed, ADAMs and ADAMTS belong to the adamalysin family, related to snake venom proteases, among which many members are implicated in different loops of reciprocal interactions with some mediators of inflammation such as TNF- $\alpha$ (Rosendahl et al, 1997; Moss et al, 2001) and growth factors including TGF- $\alpha$ and - $\beta$ (Hinkle et al, 2003; Le Pabic et al, 2003).

We describe for the first time an increased production of ADAM-12 both at the mRNA and protein levels in human lung squamous cell carcinomas and adenocarcinomas. On the opposite, we report a decreased expression of ADAMTS-1 mRNA in squamous cell carcinomas and adenocarcinomas when compared to corresponding control samples. In addition, this study provides the first evidence for a link between ADAM-12 expression and 

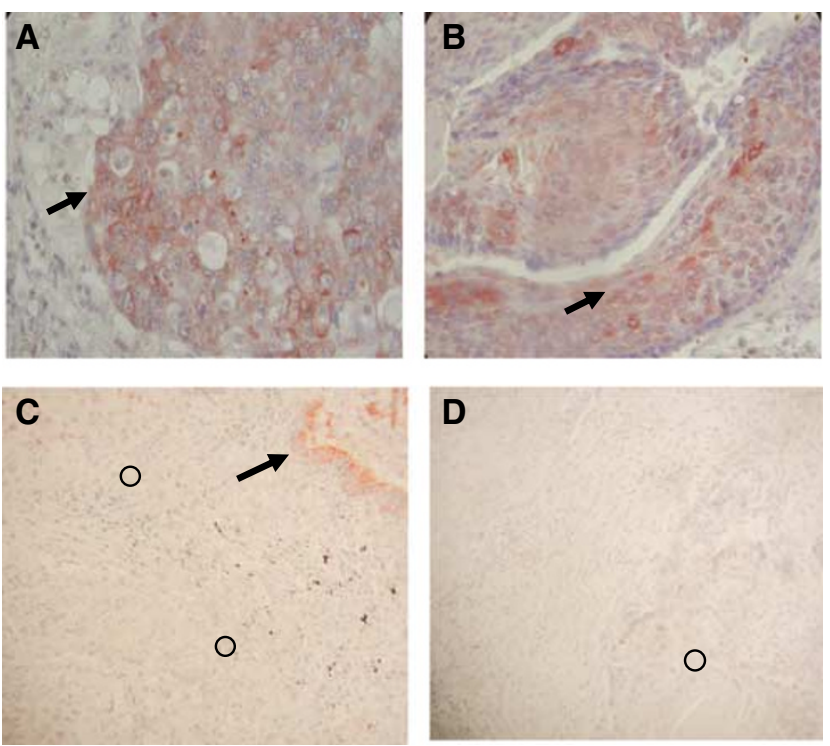

Figure 5 Immunohistochemistry. Paraffin sections of adenocarcinoma (A) and squamous cell lung cancer (B) were subjected to ADAM-I2 immunohistochemistry as reported in the Materials and Methods section. Tumour cells were strongly labelled (arrows) by anti-ADAM- 12 antibody. Paraffin sections of adenocarcinoma $(\mathbf{C})$ and squamous cell lung cancer (D) were subjected to ADAMTS-I immunohistochemistry as reported in the Materials and Methods section. Immunostaining for ADAMTS-I was localised at the level of normal bronchi surrounding the tumour (arrow) in NSCLC lung fragments while tumour cells (circles) did not display any staining with ADAMTS-I antibody.

VEGF-A $A_{121}$ or VEGF- $A_{165}$ expression. An overproduction of ADAM-12 in lung tumours has been evidenced by RT-PCR, real-time and Western blot analysis. As an alternative splicing has been reported for ADAM-12 and as the secreted short form of ADAM-12 (ADAM-12S) was described to be expressed by tumours such as rhabdomyosarcoma and HU-1 cells (Gilpin et al, 1998), we assessed our tumour samples for the expression of ADAM-12L and ADAM-12S by specific RT - PCR. Only ADAM-12L was detectable in lung cancer samples, suggesting that ADAM-12 was mainly cell membrane associated. Accordingly, Western blot analyses confirmed the presence of both pro and activated forms of ADAM-12L but not of ADAM-12S.

A disintegrin and metalloprotease- 12 overexpression in tumour samples could be related either to an increased expression by carcinoma cells themselves or by some stromal cells such as myofibroblasts surrounding tumour islets. We demonstrate in the present paper that cultured BZR lung-derived cancer cell lines expressed ADAM-12 mRNA, while 16-HBE and BEAS-2B cells derived from normal epithelial cells did not express significant levels of ADAM-12 mRNA. Others have reported an overexpression of ADAM-12 in liver carcinomas (Le Pabic et al, 2003), and its levels in urine from patients have been correlated with survival in breast cancer (Roy et al, 2004). These data, taken together with the faint expression of ADAM-12 mRNA levels in healthy lung extracts, indicate that tumour cells are probably the main producer of ADAM-12 in our experimental conditions. In accordance, immunohistochemical analysis revealed ADAM-12 production by tumour cells. The fact that invasive cell lines (BZR and BZRT33) expressed huge amounts of ADAM-12 when compared to cell lines derived from normal epithelium (BEAS-2B and 16HBE) suggests that ADAM-12 may play a role in the cascade of events leading to the invasive phenotype. As demonstrated recently, ADAM-12 could play an important role in cell adhesion (Zolkiewska, 1999; Iba et al, 2000) and, therefore, its increased expression in lung cancer cells could be mandatory for tumour cell migration and invasion through a control of cell-matrix interactions. In addition, ADAM-12 could be of particular importance in the processes leading to cell proliferation since it sheds the soluble heparinbinding epidermal growth factor (Asakura et al, 2002). Furthermore, the correlation observed between ADAM-12 and VEGF transcripts is of great interest since angiogenesis is an essential step of tumour progression. The finding of a positive correlation between ADAM-12 and VEGF- $A_{121}$ and VEGF- $A_{165}$ isoforms, which are proangiogenic, in all tumour samples reinforce the hypothesis of a specific role for ADAM-12 in tumour-associated angiogenic process. The potential effect of ADAM-12 on angiogenesis could occur either directly by activating some mediators implicated in angiogenesis as demonstrated for some MMPs or by inactivating angiogenesis inhibitors (Munaut et al, 2003; Maquoi et al, 2004; Noel et al, 2004). Alternatively and as suggested for other proteases, ADAMs could release proangiogenic factors trapped in the extracellular matrix by degrading its components (Werb et al, 1999). Nevertheless, our results are only correlative regarding the relationship between ADAM-12 and VEGF isoforms expression and further studies are needed to confirm our results and to precisely dissect the potential mechanisms linking ADAM proteases and tumour angiogenesis. The increased levels of VEGFA found in tumours associated with $\mathrm{N} 2$ states when compared to those associated with N0 is in line with a recent report (Iwasaki et al, 2004) showing that VEGF expression in tumour samples is correlated with markedly poor prognosis.

ADAMTS-1 is a secreted protein, which can bind matrix through interaction between its TS-1 motifs and heparin sulphate. It plays significant roles in organogenesis, inhibition of VEGF and fibroblast growth factor (FGF-2)-induced angiogenesis (IruelaArispe et $a l, 2003$ ) and is associated with IL-1 and LPS-induced inflammation (Kuno et al, 1997). ADAMTS-1 has been shown to bind VEGF- $\mathrm{A}_{165}$ and to inhibit VEGF- $\mathrm{A}_{165}$-stimulated VEGF-R2 phosphorylation (Luque et al, 2003). In this context, our finding of a significant decrease of ADAMTS-1 in lung cancer is of particular importance. To the best of our knowledge, the present study is the first report of a negative association between a member of ADAMTS-1 and lung cancers. Dunn et al (2004) have previously reported such a negative association for ADAMTS- 8 which was in that case associated with a promoter hypermethylation in cancers. A negative association has been demonstrated in pancreatic cancers (Masui et al, 2001) and breast cancers (Porter et al, 2004). The potential implication of ADAMTS-1 in regulation of cancer-related angiogenesis should be studied more in depth especially regarding factors stimulating or inhibiting this protease. Unveiling such factors could be particularly relevant in the setting of new therapeutic options acting through angiogenesis modulation.

In conclusion, we demonstrate in the present study that members of the ADAM and ADAMTS subfamilies are differently modulated in lung cancers suggesting different functions for individual ADAM(TS) in the development, and progression of lung carcinomas.

\section{ACKNOWLEDGEMENTS}

We thank Fabienne Perin and Cécile Caulier for their technical help. This work was supported by grants of the Fonds National de la Recherche Scientifique (FNRS, Brussels, Belgium), the Walloon Region Government, the Fondation Leon Fredericq (University of Liege), the CHU (Liege, Belgium), Action de Recherches Concertées (00/05-264, Communauté Française de Belgique), FB Assurance, Fédération Belge contre le Cancer, European Union (FP6), and the interuniversity Attraction Poles Programme Belgian Science Policy (Brussels, Belgium). DC is a scientific research worker of the FNRS and NR is granted by the Televie (FNRS-Belgium). 


\section{REFERENCES}

Asakura M, Kitakaze M, Takashima S, Liao Y, Ishikura F, Yoshinaka T, Ohmoto H, Node K, Yoshino K, Ishiguro H, Asanuma H, Sanada S, Matsumura Y, Takeda H, Beppu S, Tada M, Hori M, Higashiyama S (2002) Cardiac hypertrophy is inhibited by antagonism of ADAM12 processing of HB-EGF: metalloproteinase inhibitors as a new therapy. Nat Med 8: $35-40$

Black RA, Rauch CT, Kozlosky CJ, Peschon JJ, Slack JL, Wolfson MF, Castner BJ, Stocking KL, Reddy P, Srinivasan S, Nelson N, Boiani N, Schooley KA, Gerhart M, Davis R, Fitzner JN, Johnson RS, Paxton RJ, March CJ, Cerretti DP (1997) A metalloproteinase disintegrin that releases tumour-necrosis factor-alpha from cells. Nature 385: 729-733

Bonfil RD, Reddel RR, Ura H, Reich R, Fridman R, Harris CC, Klein-Szanto JP (1989) Invasive and metastatic potential of a v-Ha-ras-transformed human bronchial epithelial cell line. J Natl Cancer Inst 81: 587-594

Cal S, Obaya AJ, Llamazares M, Garabaya C, Quesada V, Lopez-Otin C (2002) Cloning, expression analysis, and structural characterization of seven novel human ADAMTSs, a family of metalloproteinases with disintegrin and thrombospondin-1 domains. Gene 283: 49-62

Cataldo DD, Tournoy KG, Vermaelen K, Munaut C, Foidart JM, Louis R, Noel A, Pauwels RA (2002) Matrix metalloproteinase-9 deficiency impairs cellular infiltration and bronchial hyperresponsiveness during allergen-induced airway inflammation. Am J Pathol 161: $491-498$

Dunn JR, Panutsopulos D, Shaw MW, Heighway J, Dormer R, Salmo EN, Watson SG, Field JK, Liloglou T (2004) METH-2 silencing and promoter hypermethylation in NSCLC. Br J Cancer 91: 1149-1154

Egeblad M, Werb Z (2002) New functions for the matrix metalloproteinases in cancer progression. Nat Rev Cancer 2: $161-174$

Gilpin BJ, Loechel F, Mattei MG, Engvall E, Albrechtsen R, Wewer UM (1998) A novel, secreted form of human ADAM 12 (meltrin alpha) provokes myogenesis in vivo. J Biol Chem 273: 157-166

Hajitou A, Sounni NE, Devy L, Grignet-Debrus C, Lewalle JM, Li H, Deroanne CF, Lu H, Colige A, Nusgens BV, Frankenne F, Maron A, Yeh P, Perricaudet M, Chang Y, Soria C, Calberg-Bacq CM, Foidart JM, Noel A (2001) Down-regulation of vascular endothelial growth factor by tissue inhibitor of metalloproteinase-2: effect on in vivo mammary tumor growth and angiogenesis. Cancer Res 61: 3450-3457

Handsley MM, Edwards DR (2005) Metalloproteinases and their inhibitors in tumor angiogenesis. Int $J$ Cancer 115: 849-860

Hinkle CL, Mohan MJ, Lin P, Yeung N, Rasmussen F, Milla ME, Moss ML (2003) Multiple metalloproteinases process protransforming growth factor-alpha (proTGF-alpha). Biochemistry 42: 2127-2136

Horiuchi K, Weskamp G, Lum L, Hammes HP, Cai H, Brodie TA, Ludwig T, Chiusaroli R, Baron R, Preissner KT, Manova K, Blobel CP (2003) Potential role for ADAM15 in pathological neovascularization in mice. Mol Cell Biol 23: 5614-5624

Iba K, Albrechtsen R, Gilpin B, Frohlich C, Loechel F, Zolkiewska A, Ishiguro K, Kojima T, Liu W, Langford JK, Sanderson RD, Brakebusch C, Fassler R, Wewer UM (2000) The cysteine-rich domain of human ADAM 12 supports cell adhesion through syndecans and triggers signaling events that lead to betal integrin-dependent cell spreading. J Cell Biol 149: $1143-1156$

Iruela-Arispe ML, Carpizo D, Luque A (2003) ADAMTS1: a matrix metalloprotease with angioinhibitory properties. Ann NY Acad Sci 995: $183-190$

Ishikawa N, Daigo Y, Yasui W, Inai K, Nishimura H, Tsuchiya E, Kohno N, Nakamura Y (2004) ADAM8 as a novel serological and histochemical marker for lung cancer. Clin Cancer Res 10: 8363-8370

Iwasaki A, Kuwahara M, Yoshinaga Y, Shirakusa T (2004) Basic fibroblast growth factor (bFGF) and vascular endothelial growth factor (VEGF) levels, as prognostic indicators in NSCLC. Eur J Cardiothorac Surg 25: $443-448$

Kaushal GP, Shah SV (2000) The new kids on the block: ADAMTSs, potentially multifunctional metalloproteinases of the ADAM family. J Clin Invest 105: 1335-1337

Killar L, White J, Black R, Peschon J (1999) Adamalysins. A family of metzincins including TNF-alpha converting enzyme (TACE). Ann NY Acad Sci 878: $442-452$

Kuno K, Kanada N, Nakashima E, Fujiki F, Ichimura F, Matsushima K (1997) Molecular cloning of a gene encoding a new type of metalloproteinase-disintegrin family protein with thrombospondin motifs as an inflammation associated gene. J Biol Chem 272: 556-562
Lemjabbar H, Li D, Gallup M, Sidhu S, Drori E, Basbaum C (2003) Tobacco smoke-induced lung cell proliferation mediated by tumor necrosis factor alpha-converting enzyme and amphiregulin. J Biol Chem 278: $26202-$ 26207

Le Pabic H, Bonnier D, Wewer UM, Coutand A, Musso O, Baffet G, Clement B, Theret N (2003) ADAM12 in human liver cancers: TGF-beta-regulated expression in stellate cells is associated with matrix remodeling. Hepatology 37: $1056-1066$

Luque A, Carpizo DR, Iruela-Arispe ML (2003) ADAMTS1/METH1 inhibits endothelial cell proliferation by direct binding and sequestration of VEGF165. J Biol Chem 278: 23656-23665

Maquoi E, Sounni NE, Devy L, Olivier F, Frankenne F, Krell HW, Grams F, Foidart JM, Noel A (2004) Anti-invasive, antitumoral, and antiangiogenic efficacy of a pyrimidine-2,4,6-trione derivative, an orally active and selective matrix metalloproteinases inhibitor. Clin Cancer Res 10: 4038 4047

Masui T, Hosotani R, Tsuji S, Miyamoto Y, Yasuda S, Ida J, Nakajima S, Kawaguchi M, Kobayashi H, Koizumi M, Toyoda E, Tulachan S, Arii S, Doi R, Imamura M (2001) Expression of METH-1 and METH-2 in pancreatic cancer. Clin Cancer Res 7: 3437-3443

McKie N, Edwards T, Dallas DJ, Houghton A, Stringer B, Graham R, Russell G, Croucher PI (1997) Expression of members of a novel membrane linked metalloproteinase family (ADAM) in human articular chondrocytes. Biochem Biophys Res Commun 230: 335-339

Moss ML, White JM, Lambert MH, Andrews RC (2001) TACE and other ADAM proteases as targets for drug discovery. Drug Discov Today 6: $417-426$

Munaut C, Noel A, Hougrand O, Foidart JM, Boniver J, Deprez M (2003) Vascular endothelial growth factor expression correlates with matrix metalloproteinases MT1-MMP, MMP-2 and MMP-9 in human glioblastomas. Int J Cancer 106: $848-855$

Noel A, Maillard C, Rocks N, Jost M, Chabottaux V, Sounni NE, Maquoi E, Cataldo D, Foidart JM (2004) Membrane associated proteases and their inhibitors in tumour angiogenesis. J Clin Pathol 57: $577-584$

Overall CM, Lopez-Otin C (2002) Strategies for MMP inhibition in cancer: innovations for the post-trial era. Nat Rev Cancer 2: 657-672

Porter S, Clark IM, Kevorkian L, Edwards DR (2005) The ADAMTS metalloproteinases. Biochem J 386: $15-27$

Porter S, Scott SD, Sassoon EM, Williams MR, Jones JL, Girling AC, Ball RY, Edwards DR (2004) Dysregulated expression of adamalysin-thrombospondin genes in human breast carcinoma. Clin Cancer Res 10: $2429-$ 2440

Puente XS, Sanchez LM, Overall CM, Lopez-Otin C (2003) Human and mouse proteases: a comparative genomic approach. Nat Rev Genet 4: $544-558$

Rosendahl MS, Ko SC, Long DL, Brewer MT, Rosenzweig B, Hedl E, Anderson L, Pyle SM, Moreland J, Meyers MA, Kohno T, Lyons D, Lichenstein HS (1997) Identification and characterization of a pro-tumor necrosis factor-alpha-processing enzyme from the ADAM family of zinc metalloproteases. J Biol Chem 272: 24588-24593

Roy R, Wewer UM, Zurakowski D, Pories SE, Moses MA (2004) ADAM 12 cleaves extracellular matrix proteins and correlates with cancer status and stage. J Biol Chem 279: 51323-51330

Sounni NE, Roghi C, Chabottaux V, Janssen M, Munaut C, Maquoi E, Galvez BG, Gilles C, Frankenne F, Murphy G, Foidart JM, Noel A (2004) Up-regulation of vascular endothelial growth factor-A by active membrane-type 1 matrix metalloproteinase through activation of Srctyrosine kinases. J Biol Chem 279: 13564-13574

Tang BL (2001) ADAMTS: a novel family of extracellular matrix proteases. Int J Biochem Cell Biol 33: $33-44$

Trejo YG, Bordenave RH, Beviacqua M, Zanoni L, Rumi LS (2001) Tumor necrosis factor-alfa production by monocytes from lung and colorectal cancer patients. J Exp Clin Cancer Res 20: 71-73

Werb Z, Vu TH, Rinkenberger JL, Coussens LM (1999) Matrix-degrading proteases and angiogenesis during development and tumor formation. APMIS 107: $11-18$

Wu E, Croucher PI, McKie N (1997) Expression of members of the novel membrane linked metalloproteinase family ADAM in cells derived from a range of haematological malignancies. Biochem Biophys Res Commun 235: $437-442$

Zolkiewska A (1999) Disintegrin-like/cysteine-rich region of ADAM 12 is an active cell adhesion domain. Exp Cell Res 252: 423-431 